\title{
VIDA E OBRA DO “MAIOR ARTISTA DO VERSO" NO BRASIL BREVES NOTAS NO CENTENÁRIO DE SEU FALECIMENTO
}

\author{
Antônio Martins de Araújo (UFRJ/ABRAFIL) \\ amaraujo@globo.com
}

\section{O contexto histórico}

Tantas e tão diversas as forças motrizes da fermentação social nas três décadas compreendidas entre 1870 e 1900, que a ela bem se pode aplicar, segundo já disseram, o epíteto de Renascença Brasileira. No plano político-social, o perfil da nação brasileira se transformou com a Abolição da Escravatura e a proclamação da República.

No plano da literatura, de um lado, assistiu-se à quase total substituição do Romantismo pelo Naturalismo, pelo Realismo e pelo Parnasianismo; e, de outro, pelo Simbolismo. No plano da filosofia e da sociologia, o chamado Idealismo Romântico deu lugar ao Racionalismo e ao Positivismo nas ideias.

Desde os pródromos desse período, nos centros universitários do eixo Rio-São Paulo, assistiu-se ao advento do que se convencionou chamar "Ideia Nova", trazendo em seu bojo o realismo, o socialismo, o republicanismo, o anticlericalismo, o objetivismo e o determinismo de base tainiana.

Participando ativamente tanto das lides acadêmicas paulistas, como, depois, colaborando intensamente com suas ideias nos periódicos da cidade mineira e das fluminenses por onde exerceu com a integridade de sempre a magistratura, Raimundo Correia pôde divulgar para as mentes idealistas suas progressistas posições. 


\section{Um nome nobre}

Conforme nos mostra seu principal biógrafo e editor, crítico, o acadêmico Waldir Ribeiro do Val, Raimundo Correia. foi dado à luz em plenas águas maranhenses numa rede de algodão, a bordo do navio São Luís, em $1^{\circ}$ de maio de 1859 . seu nome de batismo foi Raimundo de São Luís da Mota de Azevedo Correa.

Em sendo assim, como de fato foi, nenhum escritor maranhense, que eu saiba, teve inserido no próprio antropônimo o sinete da ilustre e histórica maranhensidade, como o fizeram seus felizes e prolíficos pais.

Em seu elegante ensaio Raimundo Correia e o seu sortilégio ver$\mathrm{bal}$, ensaio que exorna a edição crítica de que ora nos ocupamos, o poeta pernambucano Manuel Bandeira, depois de lembrar o curioso nascimento do poeta em uma rede, a bordo do navio São Luís, na baía de Mangunça (MA), a 13/05/1859, lembra que nosso poeta declarou haver vivido "uns restos de infância e toda a adolescência em Cabo Frio (RJ), onde leu à beira-mar Os Lusíadas, de Luís Vás de Camões.

Em 1942, o cônego Francisco Maria Bueno de Sequeira editou, com o selo da Academia Brasileira de Letras, seu ensaio Raimundo Correia. Sua vida e sua obra, em que afirma, com base em informação inexata de Augusto de Lima, que Raimundo Correia teria feito gratuitamente todo o curso secundário no imperial Colégio Pedro II.

Waldir Ribeiro do Val, seu mais completo biógrafo e competente editor crítico de sua obra, com base nos arquivos daquele estabelecimento, corrige-o declarando que Raimundo Correia, aos treze anos de idade, iniciou sua instrução secundária naquele tradicional estabelecimento, a partir do segundo ano, sob a matrícula 1113, em 26/01/1872, porém como aluno externo contribuinte, e não gratuitamente.

\section{O perfil humano}

De estatura franzina, rosto moreno, puxando a claro, maçãs do rosto salientes, cabelos e bigodes pretos. A barba negríssima e muito bem cuidada passou a usar após formado em Direito. Costumeiramente introvertido, às vezes, quando o assunto lhe interessava, disparava a falar pelos cotovelos.

Temia tempestades, tinha horror a doenças de qualquer espécie, detestava pegar em dinheiro e, temendo o inferno, chegou a ter pesadelos 
com o demo. A psicologia classificaria o tipo físico de Raimundo Correia como pícnico, aquele que se quebra, mas não se verga. Estes, em breves traços, o biótipo de Raimundo Correia.

\section{Leituras juvenis}

Com dezenove anos incompletos, na Faculdade de Direito de São Paulo já era colega e amigo do peito do infortunado Silva Jardim, que foi tragado pelo Vesúvio. Fumante inveterado, o maior artista do verso no Brasil, primus inter pares na trindade parnasiana (com Alberto de Oliveira e Olavo Bilac), na mocidade Raimundo Correia costumava revisitar, dentre outras obras, os Sermões do bom padre Manuel Bernardes e as sátiras picantes de Manuel Maria du Bocage, ambos portugueses de nascimento. Em tão boa companhia na adolescência, não é de admirar que, na idade adulta, Raimundo Correia tenha ampliado com obras canônicas da literatura estrangeira e da nacional, suas leituras preferenciais.

\section{O Modelo paterno}

Assim como seu pai - o respeitável Dr. José Mota Azevedo Correa -, que foi juiz municipal em Cabo Frio por duas vezes e em Paraíba do Sul, ambas comarcas do Rio de Janeiro; e mais ainda nas comarcas da Bananeira (Paraíba), Vila Nova (Sergipe), São Miguel (Santa Catarina), Bananal (São Paulo), e como desembargador em Cuiabá; seu filho Raimundo Correia segue-lhe os passos exercendo inicialmente o cargo de promotor público em São João da Barra (RJ), e depois, como juiz municipal, em Vassouras e Resende (ambos no RJ), em Turiaçu (MA), em São Gonçalo do Sapucaí (Santa Isabel) em MG; juiz da 2. ${ }^{a}$ Pretoria do antigo Distrito Federal (RJ), para onde quatro anos depois (em 1907) seria nomeado juiz de direito sucessivamente da $2^{\mathrm{a}}$ e da $5^{\mathrm{a}}$ Vara Criminal, e da $3^{\text {a }}$ Vara Cível. Esta, sua mais eminente ocupação profissional.

\section{O professor e o funcionário público}

Com a base teórica do Direito haurida em São Paulo não é de admirar que Raimundo Correia a tenha multiplicado, estendendo a outrem tão rica experiência. 
Seu nome consta da instalação da Faculdade Livre de Direito de Minas Gerais e, em 1896, é eleito catedrático de direito criminal dessa instituição. Três anos depois será nomeado professor e vice-diretor do Ginásio Fluminense de Petrópolis, porém, conforme procuraremos demonstrar, essa não é sua ocupação principal.

Sua passagem pelo serviço público também foi passageira. No segundo semestre de 1889, Raimundo Correia exerceu o cargo de secretário da presidência da província do Rio de Janeiro; e, em 1892, o de diretor da Secretaria das Finanças do estado de Minas Gerais. Com a proclamação da república, foi intensa a oferta dos novos cargos criados e Raimundo Correia foi um dos beneficiados por ela.

\section{A crítica literária}

Raimundo Correia também exerceu a crítica literária. Sem os requintes da atual teoria literária, dedicou ele a análises muito adequadas e lúcidas a obras de contemporâneos seus. Eis aqui notas sumárias sobre alguns desses estudos literários.

\subsection{Lucindo Filho}

Das várias obras literárias que comentou destaca-se a do mineiro de Diamantina, Lucindo Filho. Raimundo Correia exaltou-lhe as traduções em versos brancos de alguns poemas não só do mantuano Virgílio; mas também dos italianos Alfieri e Leopardi; dos espanhóis Zorilla e Espronceda; dos franceses Catulle Mendès e Heraedia; dos ingleses Byron Longfellow e Pope; e dos alemães Heine e Schiller.

\subsection{Múcio Teixeira}

Após formular restrições aos escritores de obras caudalosas, e elogiar os que as têm reduzidas, mas buriladas e caprichosas, Raimundo Correia critica a longa torrente de livros em versos de Múcio Teixeira, quais sejam Vozes trêmulas, Violetas, Sombras e Clarões, Flor de um dia, Cérebro e Coração; porém elogia o feliz acabamento e a cuidada tessitura de suas obras, posteriores, como Novos Ideais e Prismas e vibrações. Critica ainda seus coevos Valentim Magalhães, Fontoura Xavier, 


\section{FACULDADE DE FORMAÇÃO DE PROFESSORES}

Assis Brasil, Augusto de Lima, Filinto de Almeida e Silvestre de Lima por imitarem todos a Morte de Don Juan, de Guerra Junqueira.

\subsection{Alberto de Oliveira}

Lamentando a mudança deste, da cidade de Vassouras para a capital do Estado, Raimundo Correia compara a excelência artística dos sonetos e poemas de Alberto de Oliveira com as dos "mármores vivos" de Miguel Angelo e os painéis de Rembrandt e Goya", considerando "encantadores" os poemas "A Árvore", "A Lagarta", "Vertumno", "O Manto Real", "Titânia", "Galateia", "Sirina" e "A Agonia do Herói", em que aflora "a imaginação pagã"; bem como "O Leito de Romana", "Mármore", "A Ponte Vermelha", "A Janela e o Sol", "A Entrada da Primavera", "Ao Luar de Verona", "As Três Formigas" e a série de sonetos intitulada "Mortos Para Sempre", elogiados todos pela feliz adequação entre fundo e forma.

\subsection{Lúcio de Mendonça}

Ao chegar a São Paulo em 1878, Raimundo Correia incorporou-se à plêiade dos jovens talentos Afonso Celso Jr., Assis Brasil, Augusto de Lima, Magalhães Castro, Teófilo Dias (sobrinho do grande Gonçalves Dias) e Valentim Magalhães, todos concordes em que o mais brilhante deles foi Lúcio de Mendonça, que se formara um ano antes deles e de logo de lá se ausentou.

Raimundo Correia considera notável seu romance $O$ Marido da Adúltera, destacando-lhe o fato de propor questões de subido interesse social. Lúcio de Mendonça colaborou com poesias em $O$ Planeta do Sul (MG), no Crisálida e no União, no Rebate e no Província de São Paulo, todos esses quatro, paulistas; e, na corte do império brasileiro, na atual cidade do Rio de Janeiro, no Colibri, na Gazeta de Notícias, no Globo, no Mosquito e especialmente na República; e ainda no Vassourense, da cidade de Vassouras, bem como na Estação, da capital do estado, sendo todos fluminenses. Outrossim, Raimundo Correia crê plenamente consolidada sua técnica nos versos de suas obras Névoas Matutinas, Alvoradas e Lições do Abismo, nas quais exalta "a parcimônia regrada dos vocábulos" e "a admirável propriedade com que os distribui", antecipando-se em cerca de um século ao postulado de Roman Jakobson, segundo o qual o verso perfeito resulta da combinação do eixo da seleção vocabular com o 
eixo da combinação das palavras nas frases. Ressalta enfim que Lúcio de Mendonça redigiu e compôs graficamente o periódico Borboleta, dedicado integralmente ao belo sexo.

\subsection{Augusto de Lima}

Nos versos das Contemporâneas do poeta supracitado, do qual Raimundo Correia foi dileto colega na Faculdade de Direito de São Paulo, denuncia "a funda e indefinível saudade" na "música aprazível de seus versos." Assentindo com o juízo critico do prefácio dessa obra, transcreve ainda as palavras do também poeta Teófilo Dias: "imaginação poderosa, sensibilidade delicada, elocução espontânea, individual e própria."

Numa época em que pontificávamos positivistas, não escapa a Raimundo Correia o antirromantismo das poesias objetivistas de Augusto de lima, que negam a Deus e "estão impregnadas de uma filosofia triste e desconsoladora, e ao mesmo tempo fascinante como um abismo." Em poucas palavras, eis o que Raimundo Correia destaca na obra de seu colega e amigo.

\subsection{Sílvio de Almeida}

Após tecer judiciosas considerações sobre a inocuidade dos prefácios, neste que, a contragosto, escreveu para o livro de poemas estreantes da obra Efêmeras, de Sílvio de Almeida, Raimundo Correia também afirma que a leitura das obras dispensará o conhecimento pessoal do autor, porque ela falará por si mesma em favor de seu jovem talento. Afirma enfim que "a boa intenção que conforta e alenta o espírito" encontrada nas páginas das Efêmeras contrastam com a asfixia de quem as lê, e conclui afirmando não precisar de recomendar a obra a ninguém porque ela já se recomenda a si mesma, dispensando literatos paraninfos.

\subsection{Valentim Magalhães}

Contra a crítica negativa com que, em geral, foi recebido o romance de estreia de Valentim Magalhães - Flor de Sangue -, entre as quais avulta a falta de descrições de paisagens, Raimundo Correia lembra que num romance as peripécias são mais importantes que as descrições, 


\section{FACULDADE DE FORMAÇÃO DE PROFESSORES}

bem assim, ainda que sem base concreta, afirma que um romance nada mais é que um conto maior.

Em verdade, segundo a boa doutrina da teoria da literatura, o que opõe a novel a um romance é que, enquanto aquela é uma sucessão de episódios; esta é uma simultaneidade delas; e o conto não passa de reprodutor de uma peripécia apenas. Em um longo excurso, Raimundo Correia procura justificar e defender a verossimilhança dos personagens com os da própria sociedade de então. Enfim, em defesa de Valentim Magalhães lembra que ele não é autor de uma obra só. Dentre sua bagagem de dezessete obras publicadas até então, Valentim Magalhães publicou poemas (Cantos e Lutas); teatro, em colaboração com Filinto de Almeida (El Gran Galeoto); contos (Quadros e Contos, Vinte Contos e Bric-à-Brac) ; e também crítica literária (Escritores e Escritos). Ecce homo!

\subsection{Trajano Galvão de Carvalho}

Em prefácio aos poemas de Sertanejas desse escritor, Correia exalta-lhe a presença ostensiva da natureza. O que mais lhe impressionou, porém, foi pioneirismo de seus poemas abolicionistas, anteriores mesmo aos de Castro Alves e Fagundes Varela. Destaca ainda nosso crítico as semelhanças existentes entre o poema Lua de Londres, do poeta português João de Lemos, com o poema $O$ Brasil, do seu conterrâneo.

\section{A Padaria Espiritual}

Raimundo Correia ficou maravilhado com a iniciativa de alguns jovens escritores cearenses haverem fundado uma associação que visava aglutiná-los, não só em Fortaleza, mas também fora de lá, com o objetivo de editarem e divulgarem sua produção literária, cujas obras eram logicamente chamadas de "pães".

Em sua primeira quadra de existência, a Padaria publicou estas obras: Versos Diversos, de Antônio Sales, seu principal incentivador; Flocos, do poeta paraibano Sabino Batista; Fantos, de Lopes Filho, cujos versos nosso crítico considerou plenos de esquisitices métricas, bem ao gosto do decadentismo francês; Lopes Filho, cujos versos foram gestados "sob a influência da negra melancolia dos exilados; no Amazonas"; Antônio de Castro, com seus Versos, considerados originais por Antônio 
Sales, o corifeu da plêiade; Eduardo Saboia, com seus Contos do Ceará; e Juvenal Galeno, a cujos contos, Raimundo Correia devotava justa admiração.

Em 1895, nova "fornada de pães" saía da Padaria Espiritual, a saber: as Trovas do Norte, de Antônio Sales; os versos de Cromos, de Xavier Castro; os versos Dolentes de Sabino Batista; o romance Os Brilhantes, de Rodolfo Teófilo; as póstumas Memórias de um náufrago, de Alfredo Peixoto; os poemas Dilúculos e os Contos. ambos de José Maria Brígido; as fantasias em prosa de Mignon, de Roberto de Alencar; o festejado romance Dona Guidinha do Poço, de Oliveira Paiva; o poemeto Eremita, de Lopes Filho; e os estudos literários de Mas..., de Cabral de Alencar. Algumas dessas obras, como o romance de Oliveira Paiva, transcendeu seu espaço e ganhou fôlego pelo nosso país até nossos dias.

Ainda na ótica de Raimundo Correia, outros ilustres cearenses transcenderam a seu berço natal para brilharem na Corte, como Álvaro de Oliveira, B. Lopes, o célebre autor de Cromos, Capistrano de Abreu, Clóvis Bevilacqua e Moura Brasil; o mesmo acontecendo com os conterrâneos de nosso crítico, como os maranhenses Aluísio e Artur Azevedo, Joaquim Serra e Teófilo Dias, de quem já falamos. E conclui Raimundo Correia seu ensaio prometendo para breve outros estudos que, por várias razões, especialmente as lides da magistratura, não pôde concretizar.

Em conclusão, bendita geração a de Raimundo Correia, em que tantos brasileirinhos de todos os cantos do nosso país puderam migrar para nossas cidades grandes, especialmente as do eixo Rio de Janeiro - São Paulo, para se perpetuarem na memória de nosso povo.

\section{O legado lírico}

Como o grande Kafka, a intensa vida interior e a criatividade do espírito de Correia foram as fontes indiscutíveis de alguns sonetos e poemas famosos na lírica nacional. Nos versos de estreia Primeiros Sonhos, dos seus vinte anos, revela influência de obras poéticas de nossa segunda geração romântica, como as de Casimiro de Abreu e Fagundes Varela, mas apenas era um jovem e promissor talento.

Só a partir de sua segunda coletânea de versos é que Raimundo Correia irá produzir alguns de seus mais célebres sonetos, como os antológicos sonetos Mal secreto e As pombas que revelam a sua melancolia, e 


\section{FACULDADE DE FormaÇÃo de PROFESSORES}

outros afins que muitos de nós trazemos de cor desde os bancos escolares até a idade madura.

O então jovem poeta Ledo Ivo, hoje dos mais brilhantes membros de nosso sodalício maior, a Academia Brasileira de Letras, já chamou a atenção dos seus leitores para a presença da lua, tema recorrente em sonetos de nosso poeta, como Anoitecer, A cavalgada, Plenilúnio e Sozinha, que convencionou cognominar de "lunaridade", que ecoará no soneto Ária Noturna, da obra Versos e Versões, e em Harmonias de uma Noite de Verão, de Aleluias.

\section{Ideias epistolares}

O pesquisador e ensaísta Waldir Ribeiro do Val, em cuja obra $R a$ imundo Correia / Poesia completa e prosa principalmente nos apoiamos nestas breves notas, brindou-nos ainda com a correspondência ativa de Raimundo Correia para alguns de seus amigos mais chegados.

Nessas cartas, nosso poeta, com a transparência e a sinceridade que o caracterizavam, expende seus pontos de vista, ora elogiosos, ora restritivos sobre as obras por eles editadas, além de fornecer-lhes suas notícias pessoais e as de seus familiares. Pincemos-lhe aqui as principais ideias dessas cartas.

A Alberto de Oliveira, elogia-lhe os três poemas em prosa que publicou no Diário Mercantil (RJ), reproduzido por Raimundo Correia no Vassourense (RJ) e seu soneto sensualista Extrema Verba, naquele mesmo Diário.

A Lúcio Mendonça, a partir de Ouro Preto (MG), onde exercia a magistratura, Raimundo Correia agradece-lhe o que publicou a seu respeito na Galeria do Elogio Mútuo, no periódico A Semana, editado na Corte.

A Gaspar Silva, escreve elogiando o caráter e a inspiração poética de seu dileto amigo Olavo Bilac, autor do poema Delenda Carthago e da Tentação de Xenócrates; bem como destacou o alto nível do artigo Plágios e Plagiários, editado por Valentim Magalhães no hebdomadário fluminense A Semana.

A Luís Andrade, agradece-lhe a transcrição do seu artigo Por causa de um soneto, publicado na Revista Ilustrada e, em seguida, reproduzido em A Semana, defendendo nosso poeta da injusta pecha de plagiário. 
A Alfredo Pujol, felicita-o pelo artigo que este editou no Diário Mercantil, defendo o escritor paulista Júlio Ribeiro, cujo romance naturalista A carne fora alvo de severas restrições de parte de alguns críticos, mas sinceramente declara não concordar com todos os itens daquela defesa.

A Rodolfo Leite Ribeiro, agradece-lhe a gentileza do "belíssimo soneto" editado por ele no jornal Vassourense, e a "naturalidade e cor local, além da nitidez do estilo e correção da forma" de seus versos.

Ao cearense Antônio Sales, escreve a partir de Ouro Preto, cumprimentando-o pelos excelentes trabalhos literários produzidos pelos intelectuais participantes de sua famosa Padaria Espiritual.

Enfim, a Afonso Celso, também a partir de Ouro Preto, Raimundo Correia agradece-lhe a afetuosa dedicatória que aquele lhe formulou na abertura de seu romance Giovannina, cujos capítulos anteriormente saíram na Revista Brasileira; e, a propósito "da perda de um filhinho", desesperadamente desabafa: "Não sou feliz, nunca fui, não serei jamais."

\section{As razões da perenidade}

Não poderemos encerrar este breve ensaio sobre a vida agitada de Raimundo Correia, sem dizer duas palavras sobre as razões da perenidade de alguns de seus sonetos.

Sem medo de errar, afirmamos não haver antologia brasileira respeitável que não exiba algum imarcescível soneto do sutil e filosófico poeta maranhense.

Os limites deste ensaio não nos permitem proceder à análise literária de algum de seus mais famosos sonetos, mas não nos privaremos de mostrar alguns recursos que comprovam seu pleno domínio dos processos retóricos e poéticos de toda ordem.

Apesar de sua obra de estreia Primeiros sonhos estar eivada de influências românticas, como o saudosismo de Casimiro de Abreu, Raimundo Correia alça firme seu voo parnasiano com suas Sinfonias, obra que abre com seu famoso soneto As pombas e abriga também o soneto Mal secreto, ambos cheios daquela melancolia e desesperança que o caracterizavam na linha dos exegetas da dor, como o filósofo Schopenhauer. 
Como já mostrou o poeta e acadêmico Ledo Ivo, um dos seus encantamentos líricos dá-se com o que este chamou de "lunaridade," vale dizer, seu deslumbramento diante do brilho da lua, como as dos sonetos Anoitecer e A cavalgada. O primeiro verso deste, por exemplo, em ordem direta: "A lua banha a solitária estrada", fecha-o esta chave de ouro com prolepse do objeto direto: "A lua a estrada solitária banha.

Com pleno domínio dos recursos melódicos da organização vocabular, note-se-lhe esta bela consonância de eles laterais, como que a fazer ecoar o som de um duelo de espadas no soneto VIII-Julieta: "da valerosa espada / Espalçende a clara lâmina polida" (p. 149); e esta consonância em erres, no soneto II/Hero, sugerindo o ruído de raios rompendo o céu: "[...] ríspido farfalha / Crebo, o tufão; ferve o Helesponto irado, / E o céu da Grécia torvo e carregado / Rápido o raio rútilo retalha..." (p. 146).

Do soneto II/Graziela, extraímos este belo quiasmo de sua chave de ouro: "N doce e suavíssima Graziela, / Suavíssimo e doce Lamartine." Todos estes três exemplos foram colhidos de uma coroa de sonetos intitulada de Perfis românticos, oferecida a Machado de Assis, em que o poeta evoca oito grandes musas da literatura universal, a saber: Ofélia, Graziela, Hero, Beatriz, Natércia, Virgínia e Julieta.

Nosso poeta ainda fez publicar no Brasil as seguintes coletâneas de versos parnasianos: Versos e Versões e Aleluias; e, em Portugal, em 1898, treze composições suas intituladas simplesmente de Poesias, entre as quais se inclui seu antológico Plenilúnio. Embora mais requintados os poemas de suas últimas obras, estas não receberam do público ledor brasileiro o mesmo carinho e a mesma admiração do seu segundo livro, intitulado Sinfonias, que abriga alguns de seus mais famosos sonetos.

Conquanto nosso país celebre neste ano da graça de 2011 o primeiro centenário de seu falecimento, seus antológicos poemas estão mais vivos do que nunca no coração e na memória de todos os brasileiros, como nós. 